\title{
UNA APROXIMACIÓN A LA LÍRICA DE PAUL CELAN*
}

\section{Hugo Echagüe**}

\section{I}

Todo intento de pensar una obra literaria no puede eludir, y aun requiere, la relación con los conceptos de filósofos, ensayistas, críticos de prestigio que pueden ser vinculados con ella y que podrían así legitimar, dar cuenta de o atestiguar de su decir, darle la aparente seguridad y la transmisibilidad de las ideas. Aceptando estas aproximaciones, e incluso recurriendo a ellas, pues son imprescindibles, elegimos también afirmar la diferencia del decir poético, buscar a Celan en su poeticidad, sin pretender ninguna definición de esta presunta especificidad, que tal vez tampoco exista de modo consistente para el pensamiento, sino como el brillo, la marca, la huella del lenguaje en busca de un decir junto al discurso del pensar, y que incluso hacia él tiende según el modo de su lenguaje, y aquí, el de Paul Celan, acaso el más consistente con su propósito en la lírica contemporánea ${ }^{1}$. Celan propuso la contra-palabra (Der Meridian), no opuesta a la del pensar, pero que pueda así decir lo callado, lo eludido, lo silenciado, lo inalcanzable en el decir, que el poema pretende instalar o al menos proponer, y hasta no decir, si decir es el delimitar acabado del concepto y del sentido decibles, sino instalar, entonces, el silencio: "pusimos un silencio encima" (Stretta) $)^{2}$.

* Con escasas modificaciones, corresponde al texto de una ponencia presentada en las VII Jornadas de Filosofía y Música, "El silencio en los diversos saberes", el 30 de junio de 2005, en la Universidad Nacional de Rosario.

** Profesor en la facultad de Humanidades de la UNL. hugodaniel88@hotmail.com ${ }^{1}$ Leo en Jean-Claude Milner (2003: 11-12): “... toda frase negativa conecta con lo indefinido de ciertos posibles que, por inferencia, ella afirma. La filosofía no es menos indefinida; cualquiera que haya leído a Wittgenstein sabe que hay filósofos que no desean guiar a nadie; cualquiera que haya leído a Descartes sabe que no tomar a ningún filósofo por guía puede ser el primer paso dentro de la filosofía".

2 "Wir / taten ein Schweigen darüber" (I: 200). Confrontamos nuestras traducciones con las de Reina Palazón (Celan 1999). La interpretación de Celan es siempre 
Será éste un escrito a medio camino entre el concepto y la música del poeta que aquí se propone: Celan, poeta del silencio, y apenas como una aproximación entre otras tantas posibles que su pregnante palabra propone; también, y con todo derecho, al pensar que, a veces, dialoga con la voz del poeta. Poesía que, también, es su propio concepto; su poetología. Por eso debe también callar, en tanto "poesía", en su sentido convencional, además de las profundas razones históricas que a esto la fuerzan y que no son un agregado extrínseco, sino lo que el propio poema historiza y presenta. Queremos señalar la inutilidad de la oposición o aleación extrínseca entre un Celan "político y social" y otro modernista, y aun demostrar la inevitabilidad de su decir ("aliento... dirección y destino") sin invocar causalidades. Esto ya señala hacia una multiplicidad, una dispersión, que habría que encauzar, domesticar; pero no, proponemos entonces sólo algunas alusiones, señalamientos, diálogos, en el marco de una tarea seguramente mayor y todavía en sus inicios. (Para la lírica de Celan se debe reinventar siempre la teoría así como él incesantemente reinventa el poema). Pero si su poesía es su propio concepto, es decir, lo involucra y a veces hasta lo enuncia según su modo, como propusimos, y aún habría que desplegarlo, entonces sería un pensar de lo impensable, al menos según las oposiciones convencionales. En tal caso, la diferencia que reclamamos se asentaría en una indiferencia inicial o póstuma, una disolución que sería a la vez el eclipsarse del discurso. Sin embargo, siempre hay que comenzar de nuevo, eludiendo las fáciles conclusiones lógicas disponibles.

El poema de Celan se alza en el corazón de la más grande experiencia de aniquilación de nuestra historia cercana: ¿por qué no habría de vacilar allí el discurso, todo discurso, el lenguaje mismo? ${ }^{3}$ El poema de Celan es un nopoema, es un canto que se alza en el hueco de toda poesía, en medio del incendio, de las columnas de humo de los campos de aniquilación; es un canto en llamas; llanto sobre las ruinas; salmo de cenizas; poesía gris de arena; música del señorío de la muerte ("la muerte es un maestro de Alemania') ${ }^{4}$ y desde allí, pero sólo desde allí, y a veces, música de vida, canto de esperanza, luz de las estrellas. "Un templo todavía" (Stretta). Una

múltiple: no cifra un sentido; no es equivalente a un concepto: cada cita abre un contexto diverso, inapropiable, aunque seguramente no arbitrario.

${ }^{3}$ Ver a este respecto los testimonios que cita Steiner, 1959.

4 "der Tod ist ein Meister aus Deutschland" (I: 42). 
"Nada viviente" porque, a pesar de todo y contra todo, "nada está perdido" $(\text { ibid. })^{5}$.

\section{II}

Y sin embargo, líneas de fuerza, líneas de tensión atraviesan el poema, lo tensan, no lo dejan reposar en un discurso ya previsto y previsible. ¿De dónde vienen? ¿De la tradición o de su ruptura? ¿De cuáles y qué relaciones revelan, como las líneas entrecruzadas que en una mano van delineando un destino que no estaba allí antes de su cruce, de sus nudos? Intentemos desandar, al menos en parte, este difícil camino que pueda decir algo sobre la tremenda tensión irresuelta de esta poesía que aún vive del deslumbramiento de lo Nuevo pero que está tironeada por líneas de fuerza que la llevan hacia el pasado y a un futuro incierto, sin nombre; callado. Umbrales de la Historia. Silencio del porvenir, de lo que no llegó pero se espera en silenciosa desesperación. Ya en la Todesfuge, al menos dos tradiciones allí se entrecruzan: la alemana, la rubia Margarete, y la cenicienta Sulamita, que, como señaló Hans Mayer (1967: 202), no apuntan a ninguna síntesis, sino a dos paralelas que nunca se encuentran, cuya contradicción, agregamos, no se resuelve y aun se yuxtapone en un doble discurso cuya colisión da vida y acaso origen a su obra. Todo intento de reducir esta oposición, o al menos, alteridad, lo reduciría de modo improductivo pues del choque trágico, dramático, de estas dos historicidades nace la problematicidad del poema de Celan. Esta yuxtaposición sin solución a la vista articula su obra, es su forma, es la fuga hacia el infinito de dos líneas (éstas y otras más específicas) inconciliables pero que el poeta no piensa separados. (Todo el drama de su inexplicable reunión con Heidegger podría entenderse desde esta perspectiva). Nada quiere ni puede resolver Celan, poeta judío de lengua alemana, con esta paradoja, esta contrariedad, esta yuxtaposición, aunque tal vez señale, él lo dijo, a la Utopía. Así, en Tübingen, Jänner, el alemán, el suabo Hölderlin, es cruzado con la "barba de luz de los patriarcas" 6 . Esa contrariedad se resuelve, si así pudiese decirse, en el decir oculto, intransmisible: "Pallaksch. Pallaksch", que, como señala Pöggeler (1986: 58), tanto significaría "no" como "sí". Yuxtaposición, ambigüedad indecidible pero fuera de todo juego de lenguaje por contrariedad histórica

5 "Also / stehen noch Tempel. Ein / Stern / hat wohl Licht. / Nichts, / nichts ist verloren" (I: 204).

6 "mit / dem Lichtbart der / Patriarchen" (I: 226). 
que el poema muestra en su mutuo disenso y allí quiere sostenerlo. Parece una divisa de la lírica de Celan: la Utopía de la yuxtaposición contra toda síntesis, pero que busca, ansiosamente, una salida.

\section{III}

¿Cómo se lee a Celan? ¿Por qué su obra ofrece la impresión, y a veces no errónea, de oscura, difícil, indescifrable? ¿Por qué es tan difícil de leer? Porque se niega a la definición, a la opción, pero en el sentido de lo convencional, del arte como "ceguera" en busca de una nueva forma que vaya más allá de la catástrofe y la tiniebla, aunque para eso deba atravesar toda catástrofe y tiniebla. Es la contra-palabra, que dice "no y sí"; "sí y no", su divisa, su bandera, para abrir el tiempo y la posibilidad de construir un lugar de lo humano más allá de lo humano como ha sido hasta ahora, porque hay que ir con "cantos más allá del hombre". Porque Celan sabe que ese humanismo y ese arte desembocaron, tomaron parte en la catástrofe, entonces hay que renovarlo todo, como proponía Hölderlin, o Kropotkin. ¿Cuál es la forma de configuración de lenguaje que caracteriza la lírica de Celan? ¿La metafórica (tal vez rechazada por él mismo en tanto "absoluta"); la alegórica, con todo el prestigio de la presencia del pensamiento de Walter Benjamin; o la realista, si se le da su exacto sentido? ¿O tal vez las tres? Por eso el poema no está en lugar alguno, es u-tópico (Der Meridian). La aparente solución debería poder responder a la acuciante pregunta: ¿cómo se lee a Celan? ¿Cuál es su lectura? Sin embargo es un poetizar que problematiza hasta la lectura misma y parece todo el tiempo decir: "No es eso". Hay que reinventar el poema y, también, a su lector. Su lírica se alza en la desolación de la guerra y nada ha quedado utilizable, todo ha sido corrompido, arrancado, asesinado, también el lenguaje; hay que reinventarlo de nuevo, hay que minarlo, traicionarlo, tenderle trampas, volverlo estrecho, mínimo. Como el topito de Kafka hay que entablar una lucha con el lenguaje y perforarlo, trabajarlo por dentro, llenarlo de túneles, de giros, de rizos, de entradas falsas, huir, salir a campo abierto; inventarlo todo de nuevo; crear "paroles", contraseñas. Silencio como estrategia, como tarea de zapa en el lenguaje para inventarlo todo de nuevo. Como salía Celan en mayo del 68 con banderas negras, según la leyenda, así su lenguaje se dispone a destruir para construir todo de nuevo, con las ruinas, con los incendios, con las cenizas: "pusimos un silencio encima, / envenenado, grande, / un / verde / 
silencio, un sépalo..."(Stretta) $)^{7}$. Agujerear el lenguaje con el silencio, golpearlo, rodear sus rejas con "dos bocanadas de silencio" (Sprachgitter) ${ }^{8}$. "Una palabra aún, como ésta, y los martillos / vibran en lo libre" (Blume)?.

Si la lírica de Celan es alegórica y tal vez en parte lo sea, es alegoría de la reconstrucción de la poesía (la poesía después de Auschwitz). El Tiempo es la clave que rige a Palabra y Silencio. Pasado, Presente y Futuro se entremezclan y construyen la posibilidad de ese renacer que es el renacer de un mundo habitable. Es un Tiempo de un todo presente "hasta el vértice del Ahora" (Vor einer Kerze) ${ }^{10}$ que el poema hila pacientemente: "piensa, yo era lo que soy: / un maestro de cárceles y torres / un viento en los cipreses, un bebedor en el mar, / una palabra hacia la que desciendes ardiendo" (Wasser und Feuer ${ }^{11}$. Y así, para un renacer, para los muertos que piden atención, sin los cuales no habrá reconstrucción posible: "Brillo que no quiere consolar, brillo./Los muertos: ellos mendigan aún, Francisco", dice en $A s i{ }^{12}$. Amapola y memoria: amapola por memoria. Recuerdo con tiempo y olvido que se aman mutuamente, no se excluyen y son la posibilidad del renacer más allá de toda exclusión: "Renace, plata muerta" (Wasser und Feuer) ${ }^{13}$. También el olvido es parte del recuerdo y lo permite: amapola y memoria. Pero: "Hazme amargo / Cuéntame con las almendras" (Zäble die Mandeln) ${ }^{14}$. Los muertos nos ruegan aún y sin ellos, sin sus cenizas, que la palabra lleva y silencia a la vez, no habrá renacer.

Si de algo es alegoría la poesía de Celan es de su propio proceder poético; autoalegoría que no se cierra en un formalismo sino que abre a otras vías aunque reúne poesía y teoría de la poesía: su poetizar es su teoría;

7 "Wir / taten ein Schweigen darüber, / giftgestillt, gro $\beta$, / ein / grünes / Schweigen, ein Kelchblatt" (I: 200).

8 "zwei / Mundvoll Schweigen" (I: 167).

9 "Ein Wort noch, wie dies, und die Hämmer / schwingen im Freien" (I: 164).

10 "zum Scheitel des Jetzt" (I: 110).

11 "denk, da $\beta$ ich war, was ich bin: / ein Meister der Kerker und Türme, / ein Hauch in den Eiben, ein Zecher im Meer / ein Wort, zu dem du herabbrennst" (I: 76-77).

12 "Glanz, der nicht trösten will, Glanz. / Die Toten - sie betteln noch, Franz" (I: 108).

13 "Totes Silber, leb auf..." (I: 76).

14 "Mache mich bitter. / Zähle mich zu den Mandeln" (I: 78). 
que además puede leerse como "poesía". Pero Celan exige otro lector: de poesía y de poetología yuxtapuestas, indistinguibles. Así es posible hablar de realismo y de política y de mimesis de la historia tal vez, pero de un realismo de la forma, no del contenido meramente o de la representación: la poesía de Celan no representa el Holocausto, lo es. La fuga de la muerte es el solo dicho posible de los campos de exterminio que ninguna metáfora, ninguna representación en su sentido meramente realista alcanza.

\section{IV}

Hay modos del silencio en Paul Celan, modulaciones: hay el silencio nombrado: "dos bocanadas de silencio" (Sprachgitter); "Silencio, cocido como oro..." (Cbymiscb) ${ }^{15}$. Hay el silencio de la pobreza: "poesía y pobreza" parafraseando a Benjamin; para la aterradora nueva experiencia casi no hay palabras, o muy pocas y deben ser cuidadosa, escrupulosamente reubicadas: Stimmen. Hay el silencio de lo sin-nombre: "el lugar donde yacían tiene un nombre; no tiene ninguno" (Stretta) ${ }^{16}$. Auschwitz, Treblinka, Dachau. No tienen nombre, son no-lugares porque lo son de muerte, de aniquilación. No tendrán nombre, no son representables ni decibles y su ausencia, como la de los muertos, lo invade, lo contamina todo pero a éstos el poema quiere serles fiel: "yo yacía entre ustedes..." (ibid.) ${ }^{17}$. El Silencio es la puerta de salida hacia el nuevo arte y el nuevo mundo, porque es "debe ser entendido como el lenguaje de los olvidados" (Gellhaus 1993: 14), a quienes precisamos para ser y crear, porque nos están llamando desde el pasado que está ahora en un extenso presente interminable aun en la "majestad del absurdo" y porque nos van a llevar a las puertas del futuro, tal vez como el Angelus Novus que avanza, de espaldas, hacia el futuro (Benjamin: 82). El silencio es también el decir de la historia como lo imprevisto: Revolución o Mesías; Celan no lo dice, no lo decide, porque aún no tiene nombre ni figura, pero acecha en el tiempo y puede aparecer si se hace su lugar: "Silencio, cocido como oro, en / manos carbonizadas..." (Cbymisch) ${ }^{18}$.

Lo alemán y lo judío, amapola y memoria. Hölderlin y Kafka. ¿Cómo conciliar las líneas de fuga que se encuentran en lo infinito, como Margarete

15 "Schweigen, wie Gold gekocht..." (I: 228).

16 "Der Ort, wo sie lagen, er hat / einen Namen - er hat / keinen" (I: 198).

17 "ich lag zwischen euch" (I: 198).

18 "Schweigen, wie Gold gekocht, in / verkohlten, verkohlten / Händen" (I: 228). 
y Sulamita (Mayer)? Estas tensiones articulan la obra poética de Celan y dejan su palabra en libertad, irreductible a cualquier síntesis sino a una exterioridad radical donde, como ha sido dicho, cada poema reinventa el código porque no tiene un pasado o ese pasado hay que reconquistarlo a fuerza de golpe, de inquirir al lenguaje, torcerlo, tratarlo con dulzura, como en Tübingen, Jänner donde se evoca a la querida sombra de Hölderlin. Con el lenguaje de los asesinos hay que construir un lenguaje de vida. Tal es el sentido, o uno de ellos, de la empresa de Celan, enorme pero posible a pesar de... Para eso hay que transgredirlo, girar el aliento, darlo vuelta todo para dar testimonio del tiempo y su ruptura para construir lo Nuevo o para destruir y crear el hueco de una transformación total: "Hay que reinventar el amor, ya se sabe", había dicho Rimbaud. Hay que reinventarlo todo, la vida, el lenguaje, el poema, el tiempo, dice y hace Paul Celan.

Tensiones: otra lo es entre decir y callar y su mutua relación que no es la de una síntesis posible sino que hasta toma la forma de una yuxtaposición o de un quiasmo: callar para decir; decir como una forma del silencio, como pobreza y ausencia: "Estar, en la sombra / del estigma en el aire. // Estar para nadie y para nada. / Desconocido, / solo / para ti. // Con todo lo que allí tiene lugar, / también sin / lenguaje" (Stehen, im Schatten) ${ }^{19}$.

Esta yuxtaposición, coexistencia de elementos heterogéneos, insistimos, no es una tensión a resolver, sino que estructura el poema; tampoco es tal vez sólo su contenido, sino que es forma del poema, pero forma como contenido (Jameson 1989: 61-82), es lo que explica las exigencias de la escritura poética de Celan; es yuxtaposición: no uno u otro sino, uno y otro o tal vez una doble negación, o una doble afirmaciónnegación: uno y otro, y a la vez ni uno ni otro, porque ambos son imposibles o uno y otro y a la vez, contra toda identidad y contradicción y al mismo tiempo, así en Give The Word hay "sifetas y probilas", yuxtapuestas las dos tradiciones: no sibilas y profetas, sino "sifetas y probilas", yuxtaposición, instantaneidad, disolución.

19 "Stehen, im Schatten / des Wundenmals in der Luft. // Für-niemand-und-nichtsStehn. / Unerkannt, / für dich / allein. // Mit allem, was darin Raum hat, / auch ohne / Sprache" (II: 23). 
En Tübingen, Jänner a la figura de Hölderlin se superpone la del patriarca de "barba de luz"20, y la yuxtaposición sólo alcanza su eco, su concreción, en el lenguaje idiosincrásico, único, en el ya no lenguaje: "Palaksh. Palaksh" que es en el sentido en que aquí hablamos de silencio, como estructurante y forma y presencia/ausente en el poema; ni callar ni hablar en el lenguaje humano habitual, sino "Pallaksch. Pallaksch", lo absolutamente individual, lo subjetivo indecible, el muro de piedra de lo Real, lo que hay que decir para hacer. Al fin de todo concepto y de todo discurso, sólo lo individual puro e intransferible: "Pallaksch. Pallaksch". "La ciencia imposible del ser único", como propuso Roland Barthes (1980: 126). Sólo desde allí, desde ese abismo, si no, se recorrerá la misma historia de nuevo, la de la marioneta y el autómata.

\section{V}

Y así se explica la tensión de Celan entre presunto modernismo y lo político-histórico, entre metáfora, alegoría y realismo, pero realismo de la forma de la yuxtaposición imposible, así tal vez como un surrealismo que es vida y no estilo ni manera; entre la vida y la forma, entre el arte y la sangre y la muerte, cortes, giros, gritos, murmullos, sintaxis mínima o inexplicable, inesperada, neologismos, condensaciones, para decir lo que no puede ser dicho, por horror o por inesperado y desconocido pero que puede venir ("Käme ein Mensch"), así como en la Fuga de la muerte, en el más notable despliegue formal pues sólo así se dice el horror de la muerte y el oprobio de los campos -lo que Auschwitz silencia, la poesía, la Fuga, lo aluden, lo rozan, lo callan, pero lo dicen-, porque sólo así accede, por el choque, lo indecible al poema, por la colisión y la coexistencia como las voces de la fuga que van formando en su devenir en el tiempo de la historia los acordes de muerte de la que Alemania es el maestro, der Meister, y ordena tocar el violín y cavar para la tumba: disonancia del poema, disonancia de la historia: íntimo realismo del poema de Celan, que se abre a una vida quizá con esperanza desde el abismo de la muerte porque sólo así es posible: "Intento reproducir lingüísticamente al menos trozos extraídos del análisis espectral de las cosas, mostrarlas simultáneamente en varios aspectos e impregnaciones con otras cosas... mi supuesta afición a la abstracción y mi

20 Es cierto que se podría argumentar que ambas figuran se unen a través del mesianismo romántico, pero es conjetura y alusión que el poema no parece afirmar plenamente. Apunta, en todo caso, a la contrariedad y la dispersión. 
real ambigüedad [las considero] momentos del realismo". Paul Celan, 26 de diciembre de 1966. (Felstiner 1995: 321).

\section{Obras de Paul Celan citadas}

(1952), "Zähle die Mandeln", en Gesammelte Werke. Tomo I. Frankfurt. Suhrkamp. 1983, p. 78.

'Wasser und Feuer", en Gesammelte Werke. Tomo I. Frankfurt. Suhrkamp. 1983,

p. 76-77.

(1955), "Vor einer Kerze”, en Gesammelte Werke. Tomo I. Frankfurt. Suhrkamp. 1983, p. 110.

"Give The Word" en Gesammelte Werke. Tomo II. Frankfurt. Suhrkamp. 1983, p. 93. "Assisi", en en Gesammelte Werke. Tomo I. Frankfurt. Suhtkamp. 1983, p. 108.

(1959), "Stretta", en Gesammelte Werke. Tomo I. Frankfurt. Suhrkamp. 1983, p. 195-204.

“Sprachgitter", en Gesammelte Werke. Tomo I. Frankfurt Suhtkamp. 1983, p. 167. "Blume", en Gesammelte Werke. Tomo I. Frankfurt. Suhrkamp. 1983, p.

164.

(1960), "Der Meridian", en Gesammelte Werke. Tomo III. Frankfurt. Suhrkamp. 1983, pp. 187-202.

(1963), “Tübingen, Jänner”, en Gesammelte Werke. Tomo I. Frankfurt. Suhrkamp. 1983, p. 226.

"Chymisch", en Gesammelte Werke. Tomo I. Frankfurt. Suhrkamp. 1983, pp. 227-228.

(1967), "Stehen, im Schatten", en Gesammelte Werke. Tomo II. Frankfurt. Suhrkamp. 1983, p. 23. 1983, p. 93.

"Give The Word" en Gesammelte Werke. Tomo II. Frankfurt. Suhrkamp.

\section{Bibliografía consultada}

Celan, Paul (1999), Obras completas, Traducción de José Luis Reina Palazón, Trotta, Madrid.

Barthes, Roland (1980), La cámara lúcida, Piados, Barcelona, 1989.

Benjamin, Walter (1940), "Tesis de filosofía de la historia" en Angelus Novus. Edhasa, Barcelona, 1971, pp. 77-89.

Felstiner, John (1995) Paul Celan: Poeta, superviviente, judío, Trotta, Madrid, 2002.

Gellhaus, Axel (1993), Paul Celan 'Tübingen, Jänner'. Spuren 24. Dezember 1993. Deutsche Schillergesselschaft Marbach am Neckar.

Jameson, Fredric (1986), Documentos de cultura, documentos de barbarie. (El inconsciente político), Visor, Madrid. 
Mayer, Hans (1967) "Stretta" en La literatura alemana desde Thomas Mann. Madrid. Alianza. 1970, pp. 201-212.

Milner, Jean-Claude (2003), El paso filosófico de Roland Barthes, Amorrortu, Buenos Aires, 2004.

Pöggeler, Otto (1986) Spur des Worts. Zur Lyrik Paul Celans. AlberBroschur Philosophie. Freiburg/München.

Steiner, George (1959), "El milagro hueco" en Lenguaje y silencio, Gedisa, Barcelona, 1982, pp. 133-150.

\section{Resumen}

Es necesario precisar en qué sentido se habla de silencio en la obra de Celan. Si por un lado puede decirse que su lírica es una réplica a la imposibilidad de la poesía después de Auschwitz (Adorno) y que se alza en el marco de la aniquilación de la guerra y el nazismo que arrasó también al lenguaje (Steiner), es de modo dialéctico como esta alusión al silencio, nunca positiva y fácticamente determinable, puede ser explorada, según las líneas de tensión contrapuestas que atraviesan la lírica de Celan.

Palabras clave "Poesía", "silencio", "teoría", "historia", "contraposiciones".

\section{Abstract}

It is necessary to specify in which sense the concept "Silence" is to be used in Celan's poetry. If on one hand it can be said that his Lyric is an answer to Adorno's impossibility of poetry after Auschwitz, and that it arose in the frame of the annihilation of war and Nazism that also devastated language (Steiner), on the other hand, it is in a dialectical way that this allusion to Silence, neither positively nor factically determinable, could be explored, according to the opposing tension lines that go across Celan's Lyric.

Key words: "Poetry", "silence", "theory", "history", "oppositions". 